International Journal of Social Science And Human Research

ISSN(print): 2644-0679, ISSN(online): 2644-0695

Volume 05 Issue 01 January 2022

DOI: 10.47191/ijsshr/v5-i1-21, Impact factor-5.586

Page No: 137-144

\title{
Legal But are they Accepted? The Psycho-Social Impact of Section 377 on the Lgbtqia+ Community: Pre and Post Abolishment in Delhi NCR, India
}

\author{
Aditi Joshi ${ }^{1}$ Mehak Madan ${ }^{2}$ Khushi Narang ${ }^{3}$ Megha Aggarwal ${ }^{4}$ \\ 1,2,3,4 Jesus and Mary College, University of Delhi
}

\begin{abstract}
Historical shreds of evidence show that the LGBTQIA+ community has been fighting for their basic rights for the longest time in India. A qualitative study was conducted to analyze experiences of different individuals belonging to the community living in Delhi NCR, India. Phenomenological approach was used to assess N=13 participants who were recruited using judgement purposive sampling and one-on-one interviews over Zoom were conducted with a semi-structured form of an interview which was developed involving questions around their challenges, the sociological impact, and their psychological journey. Thematic analysis was done and six key themes emerged-1. No significant change in self-confidence and self-acceptance because of the abolishment 2. Fear of losing freedom and financial resources because of their identity 3. Greater acceptance from GenZ than any other generation 4. The law has changed but the perception and acceptance haven't 5 . Although the media representation has increased, it isn't apt. 6. Need of established government policies for LGBTQIA+ community. Further studies on a larger scale will help us determine the issues faced by the community and ways to resolve them.
\end{abstract}

KEYWORDS: LGBTQIA+, India, Qualitative study, Delhi NCR, Section-377, Phenomenological Approach

\section{INTRODUCTION}

"Any discrimination on basis of sexual orientation amounts to [a] violation of fundamental rights" -Chief Justice Deepak Mishra On September 6, 2018, The Supreme Court of India scrapped Section 377 of the India Penal Code, decriminalizing the 158-yearold colonial law which read:

"377. Unnatural offenses: Whoever voluntarily has carnal intercourse against the order of nature with any man, woman or animal, shall be punished with imprisonment for life, or with imprisonment of either description for a term which may extend to ten years, and shall also be liable to fine. Explanation: Penetration is sufficient to constitute the carnal intercourse necessary to the offense described in this section." (India Code)

A five-judge constitution bench headed by Chief Justice Dipak Mishra issued the verdict after hearing various stakeholders for four days, including gay rights activists.

The law violated a lot of rights including the right to privacy, right to equality, right to non-discrimination, right to life and liberty, and right to health. Although the law didn't use the word 'homosexual', the existence of the law, and the threat of possible punishment and arrest, allowed the authorities to use the law as a tool to harass, discriminate, and prosecute against homosexuals and organisations working with them. While this historic moment was marked the 'dawn of freedom', in reality, there is still a long way to go before the queer community in India can feel absolutely free.

Before the abolition, the queer community was 'illegal in their own country.' In a study by Rao et al., 2020, participants reported feeling pressured to conceal their sexual identity and expressed various concerns about being expressed as a 'criminal.' But, even today, the situation has not changed much; although 'legal' now, the community still faces a lot of challenges. It can be seen through various researches that there is still a lot of social stigmas attached, and the community still battles through discrimination and lack in the form of rights, healthcare needs, education, and job opportunities provided to them. This has led to them being more susceptible to mental health concerns including severe stress, anxiety, isolation, and depression. According to a study by (Bhattacharya \& Ghosh, 2020), even today, the HKT (Hijras, Kothis, and Transgender) community irrespective of their gender identities have widespread mental health issues at a critical clinical level. In another study by Priya and Kumar (2020), it was investigated if discrimination and social exclusion of transgender people remain in the Indian public space after the legal recognition of Section 377. The method of Interpretative Phenomenological Approach was used to analyze the interviews of five transgender people from Jammu city. After analyzing selected transgender people, findings revealed that transgender people face social and economic exclusion on a daily basis as a result of their gender identity. 


\section{Legal But are they Accepted? The Psycho-Social Impact of Section 377 on the Lgbtqia+ Community: Pre and Post}

Abolishment in Delhi NCR, India

\section{HISTORICAL BACKGROUND}

The concept of Homosexuality in India is not a new or a 'westernized' one. In ancient times, the transgender or the Hijra community were honored and revered and played important roles in many Hindu religious texts whether it be the Rigveda in $1500 \mathrm{BC}$ or the Ramayana in 5114 BC, or Mahabharata in 3139 BC. During the Mughal Era, the hijras held important positions in the administration and court and had religious power and authority. However, as British Colonialism spread, these experiences began to lose their significance. As a part of Britain's efforts to impose and enforce their western ideas and beliefs on its biggest colony, Lord Macaulay authored the creation of Section 377 of the IPC in 1860.

Thus, the act of engaging in sexual activity with the same sex was considered 'unnatural', and if found was liable to imprisonment. But, according to researchers and advisors, including Petter Boeckman "The premise is entirely wrong. Homosexuality is both common and highly essential in the lives of a number of species" (News Medical, 2016) According to researches, homosexuality exists in at least 1500 species of animals, including the dwarf chimpanzees, humanity's closest relative, wherein the entire species is homosexual.

\section{The struggle towards freedom}

The question of the legality of Section 377 was first brought up by NGO Naaz Foundation, who in 2001 filed a petition before the Delhi High Court questioning and challenging the validity of the law as it violated the fundamental right to life and liberty, right to health, right to privacy and dignity, right to equality and freedom of expression. Thus, finally in 2009, the court read down portions of the law, as it was in violation of basic fundamental rights. Although the judgment was a big step towards sexuality rights, it was met by a lot of contempt. BJP leader Subramanian Swamy said that "homosexuality is not a normal thing and is against Hindutva.", while Baba Ramdev said that he "could cure homosexuality through 'yoga' and it was a bad addiction." (Times of India, 2018) Ultimately, various individuals and groups outright rejected the idea, and a number of appeals were filed to the Supreme Court to recriminalize homosexuality. On 11th December 2013, the apex court overturned the judgment on the basis that the LGBTQ constituted a 'minuscule minority.' There was a barrage of criticism for the regressive judgment as it erased the basic fundamental human rights of homosexuals. Consequently, India's public discourse about LGBT rights experienced an upsurge, with high profile names like Ritu Dalmia, dancer Navtej Singh Jihar coming ahead and filing the petition, and eventually turned into a movement that led to the decriminalization in a historic movement in 2018.

\section{The battle against homophobia}

Even today, more than 3 years later after the historic decriminalization of Section 377 , the queer community is still fighting for equal rights and opportunities. Even today, a significant percentage of Indians view non-binary gender identity and queer sexual orientation as a 'Western phenomenon.' While there have been some progressive achievements such as when in June 2021, the Madras High Court banned the practice of 'conversion therapy' and recommended giving awareness training to police officers and government officials to ensure they respect LGBTQIA+ rights; sadly it is only limited, and the discrimination and homophobia among the society are still strong. This can be clearly seen when a consumer goods company Dabur retracted its advertisement showing a same-sex couple celebrating the Hindu festival Karwa Chauth after Madhya Pradesh Home Minister Narottam Mishra threatened legal action. Even today, there is a lack of official data sources about transgender communities; most continue to collect and publish data in a binary format, excluding transgender and intersex individuals. Because of lack of documentation, they don't have identity cards with their preferred name and gender identities and thus are often excluded from social security benefits. The LBGTQ community is still fighting for marriage rights, with the center arguing that "same-sex marriage was not a part of Indian Culture or law." This in turn results in a grave psychosocial impact on the community. Even after so many fights and struggles, even today, the community is battling to get societal acceptance and validation. Decriminalization is not Deregulation.

Therefore, this study aims to analyze the psycho-social impact of section 377 on the youth LBGTQIA+ community on different aspects such as self-acceptance, society's perception, the role of media and educational organization, and discrimination and harassment. Further, it aims to understand what more steps and social changes are required, as individuals, society, and government to create a more inclusive pro-LGBT environment.

\section{OTHER STUDIES}

In the sphere of LBGTQ and the impact of section 377, there aren't a lot of studies assessing the pre and post-impact of the section on the youth LBGT community. Although a few studies have been done on similar lines in other cities and age groups:

Sridhar and Jenifer (2019) undertook a study to understand the impact of Section 377 and related psychological issues of gay men in Chennai and Bangalore. The study uses a mix of qualitative and quantitative methods to understand the legal impact, psychosocial impact, and role of sexual identity in an individual's life process. The UCLA loneliness scale is used to measure the level of loneliness in the respondents. Findings indicate high levels of loneliness among the respondents and also, because of the discrimination and marital pressure there is an impact on their mental and physical well-being, which affects their sense of belongingness, leading to depression, many of them even attempting self-harm and suicide. 
Legal But are they Accepted? The Psycho-Social Impact of Section 377 on the Lgbtqia+ Community: Pre and Post Abolishment in Delhi NCR, India

\section{METHOD}

\section{Phenomenological approach}

We applied a phenomenological approach to understand the experiences of Indian individuals before and after the abolishment of the law. This law has restricted a lot of individuals from expressing who they really are and restricted people from discovering their own identity and sexuality. These experiences are something that may be the same or different for different people as living in the capital of the country and around might affect experiences differently. So the abolishment was considered as a phenomenon and the experiences and perspectives of the individuals were examined.

\section{Population and Sample}

The study sample included young adults from the age of 18-24 $(\mathrm{N}=13)$ students who are and have been a part of the LGBTQIA+ community since or before the abolishment. People belonging to Delhi NCR were interviewed in order to get the most accurate results in terms of the experiences of individuals living in a particular region. All of the individuals were college students and most of them knew about the existence of the law before it got abolished.

\section{DATA COLLECTION}

$\mathrm{N}=13$ participants were selected using Judgement sampling. One-on-one interviews were conducted from 21 st November 2021 to 2nd December 2021. Interviews took place online via Zoom and informed consent was taken prior to the interviews. Audio and video recording was done after taking both written and verbal consent of the participants both prior to and during the interview. A semi-structured form of the interview was developed with questions that revolved around the mental and social experiences \& challenges of the participants, pre and post abolishment of Section-377 in India. The number of participants was halted after $\mathrm{N}=13$ as there stood a saturation in the data collection.

\section{ANALYSIS}

A thematic analysis was done in order to assess and identify the recorded data into different themes. There was a line-by-line analysis of the data by listening and noting down the key points from each individual's recordings. The similar data or experiences found in each individual's recording produced a recurring pattern that produced certain themes. These themes were then identified and the participants were quoted accordingly in different ones which then produced the results.

\section{RESULTS}

$\mathrm{N}=13$ individuals belonging to the LGBTQIA+ community were interviewed in-depth regarding their experiences pre and post abolishment of section-377. All of the participants belonged to Delhi NCR. Table 1 provides information on the participants regarding their age, gender, sexual orientation. Six key themes were identified from all the interviews. An analytical summary of each key theme is provided down below.

Table 1 showing the Age, Gender, and Sexual Orientation of all the participants

\begin{tabular}{|l|l|l|l|}
\hline Pseudo-Synonym & Age & Gender & Sexual Orientation \\
\hline 1. Sammy & 24 & Female & Bisexual \\
\hline 2. Lacey & 19 & Female & Bisexual \\
\hline 3. Shanaya & 19 & Female & Bisexual \\
\hline 4. Zimbo & 18 & Female & Bisexual \\
\hline 5. X & 21 & Non-Binary & Pansexual \\
\hline 6. Veronica & 19 & Female & Bisexual \\
\hline 7. Samantha & 24 & Female & Pansexual \\
\hline 8. Monica & 19 & Female & Bisexual \\
\hline 9. John & 18 & Non-Binary & Bisexual \\
\hline
\end{tabular}


Legal But are they Accepted? The Psycho-Social Impact of Section 377 on the Lgbtqia+ Community: Pre and Post Abolishment in Delhi NCR, India

\begin{tabular}{|l|l|l|l|}
\hline 10. Pam & 19 & Female & Bisexual \\
\hline 11. Alice & 19 & Female & Demisexual \\
\hline 12. Rachel & 18 & Female & Bisexual \\
\hline 13. Maisy & 20 & Female & Bisexual \\
\hline
\end{tabular}

\section{No significant change in self-confidence and self-acceptance because of the abolishment}

Around $70 \%$ of the participants admitted that although they are happy that they are legally allowed to be who they are, there is no significant increase in their confidence as there still exists a taboo around the subject and that there is still a fear of judgment which stops them from coming out to people.

'If I'm being honest, now I feel like I'm not doing justice to myself- I can be out, but I don't want to be; I feel like I'm lacking-and I know it's not a race, but it feels weird. And I know that the fear of judgment is stopping me, and sometimes I become sad-why am I afraid of what other people will say-and then it just becomes a whole internal debate. So, it does bring down my self-esteem when I think about it.' [P6]

'To be honest, no, I do not think that except my friends, everyone will be as accepting or as okay with me being a part of the community. I still feel like it will be scary, or something I should hide.' [P2]

\section{Fear of losing freedom and financial resources because of their identity}

Almost all participants acknowledged that one of the main reasons that they are not planning to come out to their parents or relatives until they start earning is because of the fear of their financial resources being taken away. Many expressed fear of abandonment and an impact on their immediate safe space. They were afraid that coming out to their parents would lead to feuds and conflicts and also cost their freedom, and financial resources being taken away.

'Yes, there definitely is that fear. So, I'm not going to tell them until I become financially independent. I don't know if they will take care of my finances if I come out. That is one of the main concerns I have, and that is why I haven 't come out to them or any relatives as of yet.' [P5]

'So, I know if I come out to them, they wouldn't abandon me, but they would force me to accept that I'm straight. They would sit down with me, and make me cry, or beat it out of me, and make me say that I do not belong to the community, because I don't think they would be able to handle the label of their daughter being something which is not 'straight.' They would firstly impact my immediate safe space either physically, or verbally or mentally, and then also keep a close eye on me, and might restrict my freedom. They won't impact my education, because they know that I will obviously fight for it. But, I don't think it's about me-it's about them, and if I were to force them to accept, they might even get down to abuse.' [P6]

'My parents are very homophobic and I'm sure that they won't take it well so I haven't told them yet. They might even disown me so I am waiting to get done with college and then tell them.' [P9]

'Yes, when I was in college, it was a definite fear and it played heavily on why I didn't have any conversations with them. I have been working for two years and have my own economic resources so they don't have much control over it now and have lost the control so I don't have any fear of abandonment or loss of financial resources now. ' [P7]

\section{Greater acceptance from GenZ than any other generation}

There is a huge generational gap when it comes to the acceptance of the LBGTQ community. According to the participants, today's youth or Gen $\mathrm{Z}$ is much more accepting and open to conversations than the older generations. Almost all participants admitted that they had an easier time coming out to their friends and peers, in contrast to their parents, grandparents, relatives, teachers, etc where the participants feared judgment and punishment.

'What I have seen is my parents and everybody above them is generally non-accepting. I have seen it in their behavior, it might be my relatives, strangers, my friend's parents- that whole generation seems very homophobic and problematic to me. And this is probably because they grew up as people who learned that this was a 'strict no', whereas our generation is at least tilted towards a maybe. So, also in the coming time, I do think that the next generation will be a complete yes, where the community will be completely accepted. This is probably why I feel safer coming out to people my age, or younger than me.' [P6]

'Even if you think that the generation before will understand - they will understand only to an extent because they have been raised with this thought process' [P2] 


\section{Legal But are they Accepted? The Psycho-Social Impact of Section 377 on the Lgbtqia+ Community: Pre and Post Abolishment in Delhi NCR, India}

'We can actually unlearn a lot of things at our age but people who are from older generation won't understand at this point of time, and probably still have this homophobia in their heads that's not gonna change any time soon [P1]

\section{The law has changed but the perception and acceptance haven't.}

After years of fighting for basic rights, section 377 has been abolished but the perception of people hasn't changed. Many participants stated that they felt that the acceptance in India has not been in congruence with the law. There is definitely a lack of acceptance still even after the decriminalization of section 377 and the perception of the general population of the LGBTQIA+ community is still something to be worked on.

'Yes, definitely. Even though the law might have changed overnight, the reason why so many people including my friends are not coming out is solely because of one reason i.e. the people haven't changed. The abolishment was a huge step, but there is still a lot of room for improvement obviously. People's perception is only stopping the LGBTQ from coming out.' [P6]

'It's the law that has changed but the enforcers and the people around it have been the same. It's like backhanded comments - they are not out in the open as much, but it's like underneath you can hear it.' [P3]

'Yes, I absolutely do. The law has just been decriminalized, it has done nothing for positive acceptance. If I talk about the general population, the reach hasn't happened, and because of that, there is a need to work at the grassroots level. We have a lot of work to do, not only on acceptance but also on laws like adoption and marriage.' [P5]

\section{Although the media representation has increased, it isn't apt.}

The media has played a huge role in portraying the LGBTQIA+ community in many different ways. Participants expressed their opinions about media which included Social Media like Instagram, and also print media such as Bollywood, TV series, and news, etc. According to the participants, although both social and print media have been trying and taking steps towards normalizing conversations around LGBT, most of them fail to post correct information, and they're still movies coming in which are very offensive. All of them admitted that there is a need for better representation.

'We might have seen some more representation of the LGBT community in shows and it is definitely good. But we need more appropriate representation because in many shows we see people playing LGBT characters but the representation is not right.' [P9]

'In a lot of ways, yes. But as many as there are pro LGBT, there are also those who are against it. If we talk about social media, there is definitely more awareness- people are more aware of pronouns, which is great. But there is an equal number of people saying stuff about pronouns and saying they are grammatically incorrect. There is incorrect information, but at least people are learning. Also, there used to be so many films where there are these hyperfeminine male characters who are supposed to be gay. But I think that is where cancel culture comes into play-now they don't have the audacity to put that. Like take Dostana, it is a really funny movie, but it is really homophobic and offensive as well.' [P4]

"I feel that it is a good thing that Bollywood movies portray this community but on the other hand they show it in a very stereotypical way" [P10]

'Honestly, the commercial seems kind of forced. All the companies and groups just put the ads, and the pictures, and the slogansjust for the show, they just want to appeal to the community. They just want to make sure that they're putting something in for the sake of it. Even the movies and shows which are coming out are still so offensive-I think if they're trying they should at least do it accurately. What I feel is now that the law is decriminalized, the media is trying-but they are trying from the same mindset, which makes everything clash, and it comes out in an ugly way. If you see the trailers of Laxmi, it is very offensive.

But on the other hand, a lot of pages have come up, and have created an accepting community to come out to people, to be who they are and dress how they want.' [P6]

\section{Need for established government policies for the LGBTQIA+ community}

According to the participants, the abolishment was the first step; there are still a lot of stigmas and a lack of acceptance. The community still lacks basic rights like the option to marry, adopt, etc. The government really needs to step up and provide basic rights and policies to the LBGTQIA+ community. Participants conveyed their opinion regarding the necessity of these laws for the community to feel more protected and safe in India.

'Change the laws- not only for the LGBTQ but also for everyone. Give us adoption and marriage rights. Give us equal opportunities in terms of jobs etc- there is a need for openness and movements and open campaigns. Also, make unisex uniforms. Obviously, uniforms are important and necessary, but you don't have to divide people into a binary of male and female, and they can just be themselves even if they have to wear uniforms. [P5] 


\section{Legal But are they Accepted? The Psycho-Social Impact of Section 377 on the Lgbtqia+ Community: Pre and Post}

Abolishment in Delhi NCR, India

"Legalise marriage. It's so messed up that two people who love each other can't marry because they have the same sex organs, but random strangers can be paired up together in the name of arranged marriage. That is legal, and a trend in our country. It's like even if we did, we don't have the choice to get married. We don't have that option. Also, we don't have sex education in our country. We need to educate people about what gender identity is, what sexual orientation is. It's not like a lot of people don't want to understand it, but they have a hard time comprehending the concept of nonbinary. It's not that they are prejudiced, but they genuinely don't understand because they are conditioned in a certain way. Because all their life they have been taught that there are two genders. Most homophobes aren't homophobes, they just don't understand what it is about" [ P4]

'Have a person from our community in the parliament. Just like women have reservations in the parliament, and Lok Sabha, we can too. If our community is represented more on the political front, people would be kind of forced to accept it- they wouldn't be able to discriminate as much against them. The government can always, always do more. We really need the government to step in and support our community more.' [P11]

\section{DISCUSSION}

The present study was conducted in order to understand the psychosocial impact of section 377, pre and post abolishment on the youth LGBTQIA+ community in India. It was aimed to understand the psycho-social impact on the community on different aspects such as self-acceptance, society's perception, the role of media and educational organizations, and discrimination and harassment. It was found that most of the participants did not know about the existence before the decriminalization, and 'were shocked at the absurdity that the law existed in the first place.' Findings also revealed that 11 out of 13 participants came out to their friends for the first time, and hadn't yet opened up about their identity to their parents because of fear of judgment and abandonment. On the basis of this, six key themes were identified which elaborated on the experiences and unique individual perspectives pre and post abolishment of the section. These included the sociological challenges that the youth has to face on a day-to-day basis from society, friends, and their own families. These themes explain us a lot more about the hurdles that the people from the community have to pass through on a daily basis and how hard their life becomes at times. The social impact becomes quite heavy which also at the same time impacts the psychological state of an individual. These themes are important to note if we want to understand the world from the perspectives of the individuals who belong to the community.

A pattern that was identified revealed that although they were happy about the law being decriminalized, there was no report of any significant or big change in the level of confidence because of the law. $70 \%$ of the participants admitted that there is a fear of judgment with coming out which affects their self-esteem. Secondly, due to the lack of knowledge or the conditioning of the nonacceptance of LGBTQ in Generation Y (between 25 and 40 years old), many participants also conveyed how they fear being disowned and judged and even abused or having their financial resources taken away. This is one of the major reasons the participants felt more comfortable coming out to their friends and peers, rather than their parents at least till they start earning and are financially independent. Previous studies have also mentioned that family members' initial reactions to their children's coming out or discovering their orientation include disappointment, disapproval, disbelief, rejection, hatred, and even violence. (Ranade et al., 2016) This can disturb the child, cause stress, and stop them from opening up. A few participants mentioned that although the abolishment had not had any impact on their mental health per se, family members, relatives, and strangers' comments did impact their mental health negatively. While some of them explained how being a part of the community has impacted their mental health more negatively. "As soon as I come out to somebody, their respect for me goes down... initially it was a very rough and rocky ride for me, I pushed it down a lot because of my conditioning which led to a lot of denials and low esteem." Many mentioned how their friends also stereotype them in a sexual and negative way when they try to build friendships and relationships with people. A study by Tomori et al., (2016) tried to understand the correlation of depression and 11,992 MSM (Men who have sex with men) in 12 different cities through quantitative survey and with 363 MSM in 15 different cities through qualitative methods. It revealed that the prevalence of depression is $11 \%$ with substantial variation across sites and subgroups of MSM and there was a high prevalence of suicide rates among the MSM who were depressed. These types of studies indicate the impact of lack of knowledge and acceptance on the mental health of individuals. Another key theme that was noted is that although the media representation has increased after the abolishment it is still lacking in many ways. The media representation still needs a lot of work to overcome the bridges between the general population and their knowledge about the LGBTQIA+ community. Lastly, there is a need for established government laws for the community which would make the community feel more accepted and safe. The abolishment was just the first step, there are still a lot of laws such as that of marriage and adoption which need to be implemented. An article by Knight (2019) sheds light upon the need for more government policies for the LGBTQ community. UNESCO found that in many different parts of the countries education and training are denied to the LGBTQ community and are bullied and harassed. Government should implement elements like gender-neutral uniforms, increase the number of accessible toilets and eradicate the difficulties that occur in obtaining accurate identity documents as barriers for LGBT students and update the curriculum of sex education in textbooks. 


\section{Legal But are they Accepted? The Psycho-Social Impact of Section 377 on the Lgbtqia+ Community: Pre and Post Abolishment in Delhi NCR, India}

These themes definitely provide a lot of knowledge and perspective into a whole different world which cannot be seen through a straight individual's eye. While it is important that the first step of identifying the social and psychological impact is done, it is also important to contribute in finding solutions and ways to tackle these problems.

\section{CONCLUSION}

The present study helped us understand the many different and unique perspectives of individuals regarding the abolishment of the section. It was found that although progressive steps have been taken, there is still a lack of acceptance and awareness. Today, in India, it is really important for us as individuals, society, and government to take initiatives to educate people on different sexualities and genders and create a pro-LGBTQ environment. Even though we definitely have progressed a lot as a nation in the past 10 decades, we still have a long way to go. Awareness and education are the key aspects which we need to work on and inculcate different genders, sexes, and sexuality in children's curriculum so that from a very young age they don't differentiate between what is 'normal' and what is 'abnormal'. There were certain limitations recognized in this study. Firstly, 10 out of 13 participants identified as bisexuals which restricted our exploration throughout different sexual orientations and most of them identified as females. Secondly, since many of them were in their early teens when the law was abolished, they did not know about the existence of the law before its abolishment which may have had an impact on their perspectives and experiences. Lastly, most of the participants had not come out before the law was abolished which couldn't determine their experiences before the abolishment. Further studies on sexuality, on a larger scale, can help us understand the impact of the section and the consideration of religion and races would be a great contribution to this existing paper and different religious and racial issues do occur in congruence with sexuality issues in the society which is worth studying in a country which is secular and allows the existence of many different nations which is an advantage but also sometimes also create a barrier on the thinking about certain social issues as different groups of people have different mindsets. So studies on a larger scale would definitely be a help in understanding these issues better so that we know how to tackle them and solve them which would bring us a step closer to real progress.

\section{Data Availability}

Interview transcripts are not publicly available to ensure confidentiality and so that participants are not identifiable according to the informed consent. A table persisting of all the information has been added.

\section{Ethical Section}

Ethical committee approval was not needed as this study doesn't involve any intervention. Informed consent, confidentiality and privacy was adhered to throughout the process.

\section{Informed consent}

All individuals involved in this study had consented to participate, get themselves recorded via audio and video, and for their anonymous quotations to be used from the interview in the study.

\section{REFERENCES}

1) Bhattacharya, Shamayeta; Ghosh, Debarchana (2020). Studying physical and mental health status among hijra, Kothi and transgender community in Kolkata, India. Social Science \& Medicine, 265(),

113412-. doi:10.1016/j.socscimed.2020.113412

2) Bockting, W., Coleman, E., Deutsch, M. B., Guillamon, A., Meyer, I., Meyer, W., Reisner, S., Sevelius, J., \& Ettner, R. (2016). Adult development and quality of life of transgender and gender-nonconforming people. Current Opinion in Endocrinology.

3) Ghosh, A. (2020). After Coming Out: Parental Acceptance of Gay Men in India and the United States. ProQuest Dissertations Publishing. Published. https://escholarship.org/uc/item/2xh1408m

4) India Code: Section Details. (2021). Indiacode.nic.in. https://www.indiacode.nic.in/show-data?actid=AC_CEN_5_23_00037_186045_1523266765688\&orderno=434

5) India's Relationship with the Third Gender - UAB Institute for Human Rights Blog. (2018, October 29). Uab.edu. https://sites.uab.edu/humanrights/2018/10/29/indias-relationship-with-the-third-gender/

6) International Journal of Law Management \& Humanities. (2021, May 3). Rights of LGBTQ in India and the Struggle for Societal Acceptance.

https://www.ijlmh.com/paper/rights-of-lgbtq-in-india-and-the-struggle-for-societal-acceptance/

7) Jain, D. (2013). Impact of the Decriminalization of Homosexuality in Delhi: An Empirical Study. https://www.researchgate.net/publication/343267929_Impact_of_the_Decriminalization_of_Homosexuality_in_Delhi_A n_Empirical_Study 
8) Kar, A., \& K. A, A. (2018). LEGAL RECOGNITION AND SOCIETAL REACTION ON SEXUAL MINORITIES: REFLECTIONS ON MORAL POLICING AND MENTAL HEALTH OF LGBT COMMUNITY IN INDIA. RSC, 10(2).

9) Misra, G. (2009). Decriminalising homosexuality in India. Reproductive Health Matters, 17(34), 20-28. http://www.jstor.org/stable/40647442

10) News Medical. (2006, October 23). 1,500 animal species practice homosexuality. News-Medical.net. https://www.news-medical.net/news/2006/10/23/1500-animal-species-practice/-homosexuality.aspx

11) Priya, P., \& Kumar, A. (2020). Social Acceptance and Section 377: A Case Study of Transgender People in Jammu City. Gender Studies, 19(1), 137-156. https://doi.org/10.2478/genst-2021-0008

12) Ranade, K., Shah, C., \& Chatterji, S. (2016). Making sense: Familial journeys towards self-acceptance of gay and lesbian family members in India. The Indian Journal of Social Work, 77, 437-458

.https://www.researchgate.net/publication/327883303_Making_sense_Familial_journeys_towards_selfacceptance_of_gay_and_lesbian_family_members_in_India

13) Rao, S., Mason, C. D., Galvao, R. W., Clark, B. A., \& Calabrese, S. K. (2020b). "You are illegal in your own country": The perceived impact of antisodomy legislation among Indian sexual and gender minorities. Stigma and Health, 5(4), 451462. https://doi.org/10.1037/sah0000218

14) Rights of LGBTQ in India and the Struggle for Societal Acceptance - International Journal of Law Management \& Humanities. (2021, May 3). International Journal of Law Management \& Humanities. https://www.ijlmh.com/paper/rights-of-lgbtq-in-india-and-the-struggle-for-societal-acceptance/

15) Sarkar, M. (2021). SECTION 377 AND THE UNRESOLVED DILEMMA IN THE PUBLIC SPHERE. JOURNAL OF ENGLISH LANGUAGE AND LITERATURE (JOELL), 8(3), 1-5. http://joell.in/vol-8issue-3-2021/

16) Scroll Staff. (2021, October 26). Marriage between only "biological man" and "biological woman" valid in India, Centre tells Delhi HC. Scroll.in; Scroll.in.

https://scroll.in/latest/1008589/marriage-between-only-biological-man-and-biological-woman-valid-in-india-centre-tellsdelhi-hc

17) Section 377 is History but Young LGBT Indians Need Concrete Policies to Protect them from Bullying. (2020, October 28). Human Rights Watch.

https://www.hrw.org/news/2019/06/24/section-377-history-young-lgbt-indians-need-concrete-policies-protect-thembullying

18) Shreya Raman. (2021, June 11). Denied Visibility In Official Data, Millions Of Transgender Indians Cant Access Benefits, Services. IndiaSpend; Indiaspend.

https://www.indiaspend.com/gendercheck/denied-visibility-in-official-data-millions-of-transgender-indians-cant-accessbenefits-services-754436

19) Sridhar, R., \& Jenifer, N. R. (2019). Psychosocial Impact of IPC Section 377 on Gay Men in Chennai and Bangalore. REDEFINING PROFESSIONAL SOCIAL WORK EDUCATION AND PRACTICE IN THE PRESENT SCENARIO: A Multi-disciplinary Perspective, 9(2).

20) Sudarshan Varadhan. (2021, June 7). Indian court calls for sweeping reforms to respect. LGBT rights. Reuters; Reuters. https://www.reuters.com/world/india/indian-court-calls-sweeping-reforms-respect-lgbt-rights-2021-06-07/

21) TIMESOFINDIA.COM. (2018, July 10). Being gay is against Hindutva, it needs a cure: BJP MP Subramanian Swamy. The Times of India; Times Of India.

https://timesofindia.indiatimes.com/india/being-gay-is-against-hindutva-it-needs-a-cure-bjp-mp-subramanianswamy/articleshow/64927333.cms

22) Tomori, C., McFall, A. M., Srikrishnan, A. K., Mehta, S. H., Solomon, S. S., Anand, S., Celentano, D. D. 2016. "Diverse Rates of Depression Among Men Who Have Sex with Men (MSM) Across India: Insights from a Multi-site Mixed Method Study." AIDS and Behavior 20 (2): 304-316.

23) Wandrekar, J. R., \& Nigudkar, A. S. (2020). What Do We Know About LGBTQIA+ Mental Health in India? A Review of Research From 2009 to 2019. Journal of PsychosexualHealth, 2(1), 26-36.

https://doi.org/10.1177/263183182091812 